\title{
Adiposopathy: The Role of "Sick Fat" in Cardiovascular Diseases and Exercise Mediated Improvement in Adipose Tissue Function
}

\author{
Poonam Punjabi ${ }^{1}$ and Sandeep Kumar Mathur ${ }^{2}$ \\ ${ }^{1}$ Department of Physiology, Rajasthan University of Health Sciences, India \\ ${ }^{2}$ Department of Endocrinology, Rajasthan University of Health Sciences, India
}

Submission: December 15, 2020; Published: January 08, 2020

*Corresponding author: Poonam Punjabi, Department of Physiology, Rajasthan University of Health Sciences, SMS Medical College, Rajasthan, India

Abstract

Background and aims: Positive calorie balance disrupt the function of visceral adipose tissue including cardiac and perivascular adipose tissue. Excess fat in visceral adipocytes impairs endocrine as well as immune response. The inflammatory and hormonal factors released from adipose tissue play a central role in inter-organ cross-talk. This review considers the current evidence on the role of Adiposopathy on cardiovascular disease and the importance of physical activity in restoring the function of adipocytes.

Methods: Literature searches were conducted with key words (e.g., Adiposopathy, cardiovascular disease, Exercise) using PubMed, MEDLINE, EMBASE, Science Direct, Google Scholar and DOAJ. All article types were included in the search.

Results: The pathological mechanisms associated with up-regulated proinflammatory and down-regulated anti-inflammatory cytokines are responsible for the disturbed communication among muscle, liver and vasculature. In other words, Adiposopathy promote cardiovascular risk factors such as atherosclerosis, hypertension, insulin resistance, dyslipidaemia and prothrombotic state which in turn, directly and indirectly, promotes cardiovascular disease.

Conclusion: Although various studies have identified a relationship between Adiposopathy and its contribution in pathogenesis of cardiovascular disease, further investigations into the underlying mechanisms are needed. Further, studies on the role of exercise in improving the quality of adipose tissue for the prevention and management strategies for improving cardiovascular health are suggested.

Keywords: Adipose tissue; Sick fat; Cardiovascular disease; Physical activity; Inflammation

Highlights

a) Excess fat deposition in adipose tissue derange the internal milieu of the proinflammatory and anti-inflammatory cytokines.

b) This altered milieu disturbs the normal functioning of adipocytes and interfere in the crosstalk among liver muscle and vasculature.

c) The changes brought by these cytokines have profound effect on potentiating cardiovascular risk factors (CVD).

d) Exercise promotes fat mobilization from adipocytes as well as rebrowning of white adipose tissue and improves CVD risk factors.

\section{Introduction}

The Greek Physician Hippocrates (460-377 BCE) wrote "It is very injurious to health to take in more food than the constitution will bear when, at the same time, one uses no exercise to carry off this excess. For as aliment fills, and exercise empties the body, the result of an exact equipoise between them must be, to leave the body in the same state they found it, that is, in perfect health" Bays [1]. Over the last few decades there has been a growing body of evidence which emphasized the same fact that an imbalance between energy intake and energy expenditure is responsible for excess body weight Hill \& Melanson [2] Hill [3], Caudwell [4], Romieu [5]. The excess energy intake and its storage beyond the physiological limit disturb the homeostatic milieu of fat storage depots. This excess storage and sedentary behaviour promote many diseases like obesity, diabetes, hyperlipidaemia cardiovascular disease and hypertension see Figure 1, Pang [6]

The white adipose tissue has an important role in energy homeostasis. It stores excess energy as triglycerides and releases fatty acids during energy deprivation Langin [7]. There are two 


\section{Current Research in Diabetes \& Obesity Journal}

main depots of white adipose tissue: subcutaneous and visceral. Both these depots arise from different origin during development so each one has its unique structural and functional features Farb \& Gokce [8]. Approximately $80 \%$ of total fat is stored in subcutaneous adipose tissue located in gluteal, femoral and abdominal regions. Visceral adipose tissue which accounts for $20 \%$, surrounds internal organs like omental depot, the mesenteric depot around the intestines, retroperitoneal fat around the kidney, epicardial fat, perivascular fat along blood vessels Pandzic Jaksic V [9]. Those individuals who are genetically/environmentally suscep- tible, the accumulation of excess fat in visceral adipocytes result in functional impairment of adipocytes. Adiposopathy, a term used to describe adipose tissue pathology analogous to nephropathy, myopathy, cardiomyopathy, encephalopathy, retinopathy, enteropathy, and neuropathy. Abnormally enlarged adipocytes exhibit functional abnormalities that directly and indirectly promote cardiovascular diseases Bays [1]. The aim of this review is to focus on pathologic adipose tissue and its role in increasing the risk of cardiovascular diseases and how physical activity is helpful in combating the ill effects of adenopathy.

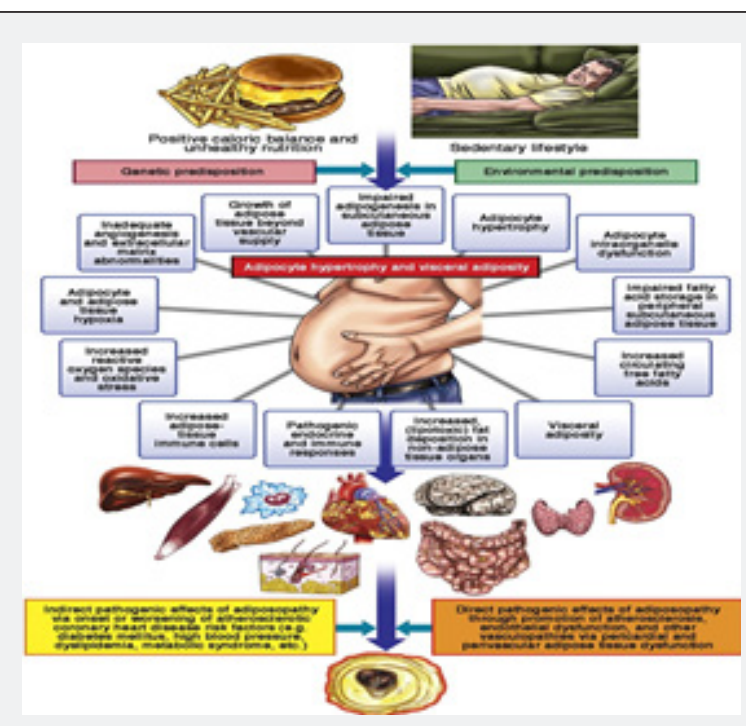

Figure 1: Adiposopathy is promoted by unhealthy nutrition and a sedentary lifestyle in genetically and environmentally predisposed individuals. With impaired adipogenesis of peripheral, subcutaneous adipose tissue during positive caloric balance, existing fat cells may hypertrophy, circulating free fatty acids may increase, and lipids may be deposited in nonadipose tissue organs (e.g., liver, muscle, possibly pancreas) resulting in lipotoxicity. Adiposopathic endocrine and immune responses may be directly pathogenic to the cardiovascular system or otherwise interact with other body systems. If not mitigated by these other body organs, adiposopathy may indirectly cause or promote major atherosclerotic risk factors (type 2 diabetes mellitus, high blood pressure, or dyslipidemia). Figure illustration by Craig Skaggs. Adopted from Bays [25].

\section{Adenopathy and Cardiovascular Disease}

In addition to storage of excess energy, adipose tissue also serves as an endocrine and immune organ capable of releasing a number of biologically active compounds involved in glucose metabolism (e.g. adiponectin, resistin), lipid metabolism (e.g. cholesteryl ester transfer protein, CETP), inflammation (e.g. TNF- $\alpha$, IL-6), coagulation (PAI-1), blood pressure (e.g. angiotensinogen, angiotensin II), and feeding response (leptin) Hajer [10]. These inflammatory and hormonal factors play important role in inter-organ crosstalk Zhu \& Scherer [11] which in turn affect metabolism and function of tissues including muscle, liver and vasculature. A number of studies have reported that up-regulation of proinflammatory adipokines and the down-regulation of anti-inflammatory adipokines in pathologic adipose tissue contributes to the pathogenesis of cardiovascular diseases Kilic [12], Fuster [13] Figure 2. A pro-inflammatory cytokine IL-6 has direct action in promoting the expression of adhesion molecules in endothelial cells and lymphocytes Bacchiega [14]. It also acts as a primary determinant of acute phase protein production and has pro-thrombotic effects on platelets and lipid accumulation in macrophages Reiss [15].

However, some studies have also documented atheroprotective properties of IL- 6 as it handles lipids through up-regulation of ATP binding cassette transporter (ABC) A1, a protein involved in macrophage lipid efflux Madan [16], Reiss [15]. These contrasting features of IL- 6 in atherogenic and atheroprotective functions need further clarification. TNF-alpha another proinflammatory cytokine, over expresses in dysfunctional adipose tissue and plays a significant role in insulin resistance by altering insulin signalling Borst [17], Nieto-Vazquez [18], Guillemette [19]. Likewise, the study by Saad [20] maintains that besides free fatty acids and hyperinsulinemia, TNF- $\alpha$ induces activation of serine/threonine kinases that phosphorylate Insulin Receptor Substrate (IRS-1) in serine and inhibits its function. Furthermore, the down-regulation 
of insulin signalling through IRSs/PI3K/Akt pathway and an increased activation of Extracellular-Signal-Regulated Kinase (ERK) pathway contributes to endothelial dysfunction. It is worth noting that animal, as well as humans, studies have supported the role of these pathways in endothelial dysfunction Campos-Mota [21], King [22]. In addition to these proinflammatory cytokines, resistin levels are also increased and have been proposed to be associated with calcification in coronary arteries Lee [23], Fuster [13]. Furthermore, Plasminogen Activator Inhibitor 1 (PAI-1) is also up-regulated in dysfunctional adipose tissue and contributes to thrombotic disorders in individuals with "sick fat" Ouchi [24]. On the other hand, adiponectin and Secreted Frizzled-Related Protein 5 (SFRP5) anti-inflammatory adipokines have atheroprotective function and its expression has been found to be decreased in adiposopathy Fuster [13]. Collectively, these studies have suggested that adiposopathy worsen CVD risk factors such as insulin resistance, prothrombotic state, dyslipidemia and hypertension which in turn indirectly promotes cardiovascular disease Bays [25].

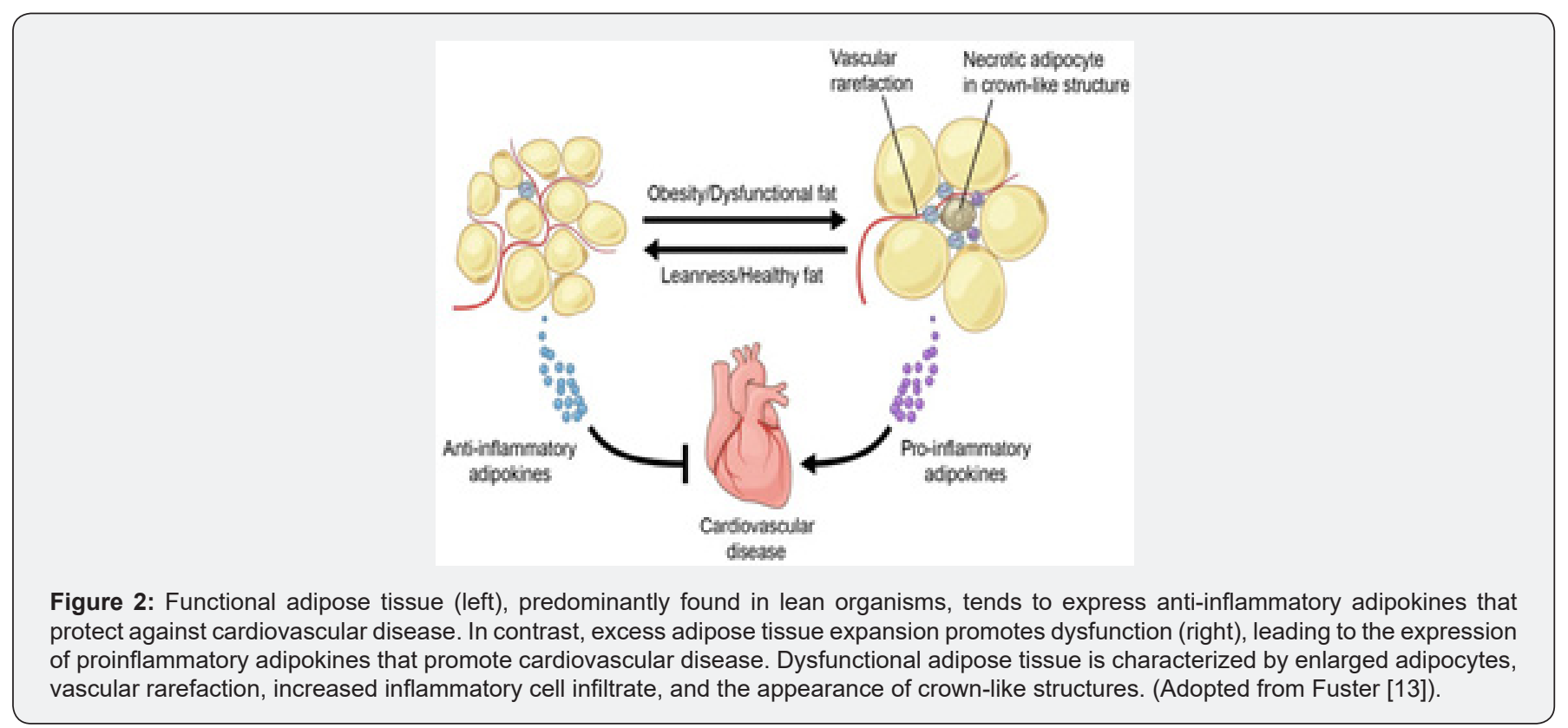

Besides, visceral adipose tissue, other ectopic fat depots such as peri-vascular, pericardial, epicardial, perimuscular and paraosseal are also metabolically active Bays [26]. Similar to visceral adipose tissue, Perivascular Adipose Tissue (PVAT) also secrete adipokines and other substances, including hormones, cytokines, chemokines, fatty acids, components of the renin-angiotensin system and oxygen radicals Houben [27]. The study conducted by Baker and his colleagues Baker [28] have shown that epicardial adipose tissue which is located between the myocardium and the pericardium expresses a pathogenic profile of adipocytokines in patients with cardiovascular disease. Another study conducted by Lee [23] has reported that dysfunctional perivascular adipose tissue may stimulate smooth muscle cell proliferation and the progression of atherosclerosis in high-fat, diet-induced obese Zucker rats. Moreover, it was also reported in the same study that the amount of epicardial adipose tissue has shown a stronger correlation with coronary artery disease than VAT in obese as well as non-obese population. A systemic review and meta-analysis conducted by Nerlekar [29] concluded that increased amount of epicardial adipose tissue is associated with the presence of highrisk plaque. When considering all the points outlined above, these studies support the notion that epicardial and perivascular dysfunctional adipose tissue have direct pathogenic effects on the myocardium and coronary arteries.

\section{Role of Physical Activity in Modulating Adipose Tissue Function}

Various epidemiological studies have shown a higher incidence of cardiovascular diseases in people who are physically inactive Elffers [30]. Sedentary lifestyle and positive calorie balance promote pathogenic adipose tissue in genetically and environmentally susceptible individuals Bays [31]. Excess fat deposition in adipocytes may lead to hypoxia which in turn inhibits adipocyte differentiation from preadipocytes. Moreover, reduced oxygen availability to adipose tissue initiate the polarisation of macrophages from M2 to M1 and cause an imbalance in anti-inflammatory and pro-inflammatory cytokines Bays [1], Ae [32]. This dysregulated adipocytokines secretion contributes to metabolic and increased CVD risk. The M1 macrophages produce pro-inflammatory cytokines and induce chronic inflammatory states whereas M2 macrophages produce anti-inflammatory cytokines and decrease this chronic inflammation Ouchi [24] Figure 3. 


\section{Current Research in Diabetes \& Obesity Journal}

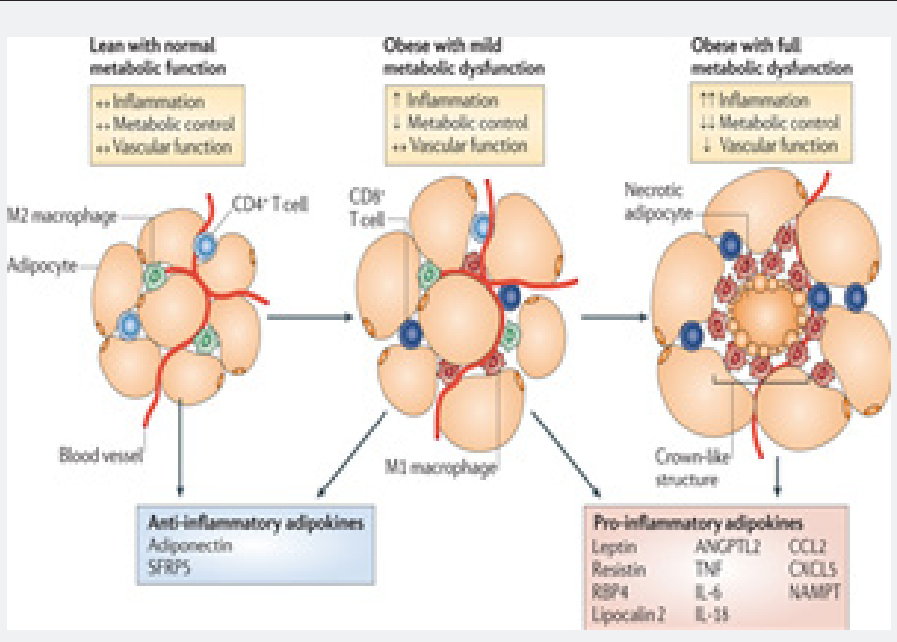

Figure 3: Macrophages in lean adipose tissue express markers of an M2 or alternatively activated state, whereas obesity leads to the recruitment and accumulation of M1 or classically activated macrophages, as well as T cells, in adipose tissue. Anti-inflammatory adipokines, including adiponectin and Secreted Frizzled-Related Protein 5 (SFRP5), are preferentially produced by lean adipose tissue. (Adopted from Ouchi [24]).

The role of physical activity in modulating the function of adipose tissue has been well documented in animal and human studies Vieira [33], Kruger [34]. Exercise training not just decreases invasion of macrophages in fat tissue yet phenotype changing from M1 to M2 is likewise incited Goh [35]. However, the molecular mechanisms responsible for these changes are still unclear Kawanishi [36]. The investigation directed by Disanzo \& You [37] observed that exercise training reduces lactate levels in intra-abdominal adipose tissue with synchronous increment in Vascular Endothelial Growth Factor A (VEGF-A), which is responsible for tissue angiogenesis and capillary growth Van Pelt [38]. A systemic review and meta-analysis conducted by Vissers [39] investigated the effect of exercise on visceral adipose tissue in overweight adults. The studies published between 1990 to August 2012 were included in this meta- analysis. It was concluded that an aerobic exercise program is effective in reducing in visceral adipose tissue more than $30 \mathrm{~cm}^{2}$ (on CT analysis) in women and more than $40 \mathrm{~cm}^{2}$ in men, even without hypo caloric diet. Regular exercise reduces the adipocyte size as well as the content of lipid stored in it. In addition to improvement in distorted adipocytes, increased expression of genes involved in mitochondrial biogenesis and activity have additionally been observed to be associated with exercise training Stanford [40].

\section{Physical Activity and Re-Browning of White Adipose}

\section{Tissue}

Human cardiac and perivascular adipose tissue belong to brown adipose tissue in early life but with age and excess fat, it whitens and becomes dysfunctional that contributes to atherogenesis in local vessels Aldiss [41]. It is well known that brown adipose tissue has a high density of mitochondria with high levels of expression of Uncoupling Protein 1 (UCP1), which is responsible for non-shivering thermogenesis Stanford [40]. It has been suggested in several studies that re-browning of white adipose tissue reduces cardiovascular risk by attenuating local inflammation and hypoxia Sanchez-Delgado [42], Aldiss [41]. During exercise, contracting muscles release bioactive molecules known as myokines, responsible for altering the metabolic phenotype of adipose tissue. These myokines also induce browning and increase fatty acid oxidation in adipose tissue Boa [43]. One such myokine, Irisin has a potential role in the browning of adipose tissue Choi [44], Winn [45] Figure 4 Choi [44], Winn [45]. Animal studies have demonstrated that physical exercise stimulate the expression of peroxisome proliferator-activated receptor-gamma co-activator 1-alpha (PGC-1 $\alpha$ ) which increases the gene expression of Fibronectin type III Domain-Containing protein 5 (FNDC5) that encodes Irisin. Above all, PGC- $1 \alpha$ is a transcriptional co-activator of Peroxisome Proliferator-Activated Receptor gamma (PPAR- $\gamma$ ). PPAR- $\gamma$ in turn modulates Uncoupling Protein 1 (UCP-1) expression in mitochondria Rodrigues et al., Exercise induced increase in PPAR- $\gamma$ mediated signally also improves serum lipid profiles (increased HDL-cholesterol and decreased total cholesterol, LDL-cholesterol, and triglycerides) and M2 macrophage activation in adipose tissue Goh [35]. In Conclusion, accumulation of fat in visceral adipose tissue beyond its limit lead to pathologic changes. These adiposopathic changes disturb the inflammatory and metabolic milieu of adipose tissue and this disturbed milieu, directly and indirectly, contribute to increased risk of cardiovascular diseases. Regular physical activity initiates a number of mechanisms at the molecular level that not only restores normal functioning of adipose tissue but initiates its browning also. The transformation of white adipose tissue into brown adipose tissue is helpful in restoring energy balance and reduces the risk of cardiovascular diseases. 


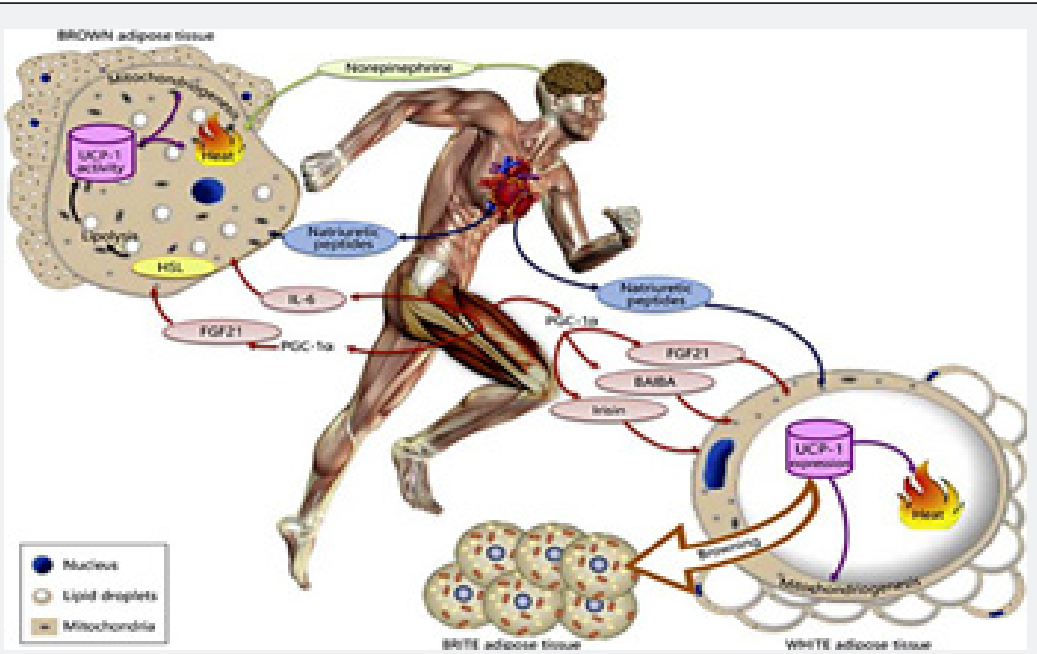

Figure 4: Potential role of exercise in the activation of BAT. Adopted from Sanchez-Delgado [42].

\section{Future Implications}

There are still some questions that need researching such as

1) what causes the defect in the process of expansion of adipocytes?

2) what is the triggering mechanism that causes good quality fat into sick fat? and

3) what initiates the macrophage polarization from M2 to M1?

a) Studies investigating the optimal exercise dose in terms of duration and intensity able to stimulate, activate and recruit BAT are also warranted.

\section{References}

1. Bays, H. 2014. Adiposopathy, "Sick Fat," Ockham's Razor, and Resolution of the Obesity Paradox. Current Atherosclerosis Reports, 16: 409.

2. Hill JO, Melanson EL (1999) Overview of the determinants of overweight and obesity: current evidence and research issues. Med Sci Sports Exerc 31(11): S515-S521.

3. Hill JO, Wyatt HR, Peters JC (2012) Energy Balance and Obesity. Circulation 126(1): 126-132.

4. Caudwell P, Gibbons C, Finlayson G, Näslund E, Blundell J (2013) Physical Activity, Energy Intake, and Obesity: The Links Between Exercise and Appetite. Current Obesity Reports 2: 185-190.

5. Romieu I, Dossus L, Barquera S, Blottière HM, Franks PW, et al. (2017) Energy balance and obesity: what are the main drivers? Cancer Causes Control 28(3): 247-258.

6. Pang G, Xie J, Chen Q, Hu Z (2014) Energy intake, metabolic homeostasis, and human health. Food Science and Human Wellness 3(3-4): 89-103.

7. Langin D (2011) In and Out: Adipose Tissue Lipid Turnover in Obesity and Dyslipidemia. Cell Metabolism 14(5): 569-570.

8. Farb MG, Gokce N (2015) Visceral adiposopathy: a vascular perspective. Horm Mol Biol Clin Investig 21(2): 125-136.

9. Pandzic Jaksic VGD (2016) Under the surface of subcutaneous adipose tissue biology. Acta Dermatovenerol Croat 24(4): 250-260.
10. Hajer GR, Van Haeften TW, Visseren FLJ (2008) Adipose tissue dysfunction in obesity, diabetes, and vascular diseases. Eur Heart J 29(24): 2959-2971.

11. Zhu Q Scherer PE (2017) Immunologic and endocrine functions of adipose tissue: implications for kidney disease. Nat Rev Nephrol 14(2): 105-120.

12. Kilic T, Ural D, Ural E, Yumuk Z, Agacdiken A, et al. (2006) Relation between proinflammatory to anti-inflammatory cytokine ratios and long-term prognosis in patients with non-ST elevation acute coronary syndrome. Heart 92(8): 1041-1046.

13. Fuster JJ, Ouchi N, Gokce N, Walsh K (2016) Obesity-Induced Changes in Adipose Tissue Microenvironment and Their Impact on Cardiovascular Disease. Circulation Research, 118(11): 1786-1807.

14. Bacchiega BC, Bacchiega AB, Usnayo MJG, Bedirian R, Singh G, et al. (2017) Interleukin 6 Inhibition and Coronary Artery Disease in a HighRisk Population: A Prospective Community-Based Clinical Study. J Am Heart Assoc 6(3): e005038.

15. Reiss AB, Siegart NM, De Leon J (2017) Interleukin-6 in atherosclerosis: atherogenic or atheroprotective? Clinical Lipidology 12(1): 14-23.

16. Madan M, Bishayi B, Hoge M, Amar S (2008) Atheroprotective Role of Interleukin-6 in Diet- and/or Pathogen-associated Atherosclerosis using an ApoE Heterozygote Murine Model. Atherosclerosis 197(2): 504-514.

17. Borst SE (2004) The role of TNF- $\alpha$ in insulin resistance. Endocr 23(23): $177-182$.

18. Nieto Vazquez I, Fernández Veledo S, Krämer DK, Vila Bedmar R, Garcia Guerra L, et al. (2008) Insulin resistance associated to obesity: the link TNF-alpha. Arch Physiol Biochem 114(3): 183-194.

19. Guillemette L, Lacroix M, Battista MC, Doyon M, Moreau J (2013) Elevated Circulating Levels of Tumor Necrosis Factor Alpha (TNF\&\#x3b1;) are Associated with Lower \&\#x3b2; Cells Compensation and Higher Insulin Resistance During Pregnancy. Canadian Journal of Diabetes 37: S81.

20. Saad MJA (2018) Chapter 44 - Obesity, Diabetes, and Endothelium: Molecular Interactions A2 - Luz, Protásio L Da In: Libby P, Chagas ACP, Laurindo FRM (eds.) Endothelium and Cardiovascular Diseases. Academic Press. 
21. Campos Mota GP, Navia Pelaez JM, Araujo Souza JC, Stergiopulos N, Capettini LSA (2017) Role of ERK1/2 activation and nNOS uncoupling on endothelial dysfunction induced by lysophosphatidylcholine. Atherosclerosis 258: 108-118.

22. King GL, Park K, Li Q (2016) Selective Insulin Resistance and the Development of Cardiovascular Diseases in Diabetes: The 2015 Edwin Bierman Award Lecture. Diabetes, 65(6): 1462-1471.

23. Lee HY, Després JP, Koh KK (2013) Perivascular adipose tissue in the pathogenesis of cardiovascular disease. Atherosclerosis 230(2): 177184.

24. Ouchi N, Parker JL, Lugus JJ, Walsh K (2011) Adipokines in inflammation and metabolic disease. Nat Rev Immunol 11(2): 85-97.

25. Bays HE (2011) Adiposopathy: Is "Sick Fat" a Cardiovascular Disease? J Am Coll Cardiol 57(25): 2461-2473.

26. Bays HE, González Campoy JM, Henry RR, Bergman DA, Kitabchi AE, et al. (2008) Is adiposopathy (sick fat) an endocrine disease? Int J Clin Pract 62(10): 1474-1483.

27. Houben AJ, Eringa EC, Jonk AM, Serne EH, Smulders YM, et al. (2012) Perivascular Fat and the Microcirculation: Relevance to Insulin Resistance, Diabetes, and Cardiovascular Disease. Curr Cardiovasc Risk Rep 6(1): 80-90.

28. Baker AR, Silva DANF, Quinn DW, Harte AL, Pagano D, et al. (2006) Human epicardial adipose tissue expresses a pathogenic profile of adipocytokines in patients with cardiovascular disease. Cardiovascular Diabetology 5: 1 .

29. Nerlekar N, Brown AJ, Muthalaly RG, Talman A, Hettige T, et al. (2017) Association of Epicardial Adipose Tissue and High-Risk Plaque Characteristics: A Systematic Review and Meta-Analysis. J Am Heart Assoc 6(8): e006379.

30. Elffers TW, De Mutsert R, Lamb HJ, De Roos A, Willems Van Dijk K, et al. (2017) Body fat distribution, in particular visceral fat, is associated with cardiometabolic risk factors in obese women. Plos One 12(9): e0185403.

31. Bays HE (2009) “Sick Fat," Metabolic Disease, and Atherosclerosis. The American Journal of Medicine 122(1): S26-S37.

32. AE 2017 Adipose Tissue Hypoxia in Obesity and Its Impact on Preadipocytes and Macrophages: Hypoxia Hypothesis. Advances in Experimental Medicine and Biology. Springer, Cham.

33. Vieira VJ, Valentine RJ, Wilund KR, Antao N, Baynard T, et al. (2009) Effects of exercise and low-fat diet on adipose tissue inflammation and metabolic complications in obese mice. Am J Physiol Endocrinol Metab 296(5): E1164-E1171.
34. Krüger K, Mooren FC, Eder K, Ringseis R (2014) Immune and Inflammatory Signaling Pathways in Exercise and Obesity. Am J Lifestyle Med 10(4): 268-279.

35. Goh J, Goh KP, Abbasi A (2016) Exercise and Adipose Tissue Macrophages: New Frontiers in Obesity Research? Front Endocrinol $7: 65$.

36. Kawanishi N, Yano H, Yokogawa Y, Suzuki K (2010) Exercise training inhibits inflammation in adipose tissue via both suppression of macrophage infiltration and acceleration of phenotypic switching from M1 to M2 macrophages in high-fat-diet-induced obese mice. Exerc Immunol Rev 16: 105118.

37. Disanzo B, You T (2013) Effects of Exercise Training on Indicators of Adipose Tissue Angiogenesis and Hypoxia in Obese Rats. Metabolism 63(4): 452-455.

38. Van Pelt DW, Guth LM, Horowitz JF (2017) Aerobic exercise elevates markers of angiogenesis and macrophage IL- 6 gene expression in the subcutaneous adipose tissue of overweight-to-obese adults. J Appl Physiol 123(5): 1150-1159.

39. Vissers D, Hens W, Taeymans J, Baeyens JP, Poortmans J, et al. (2013) The Effect of Exercise on Visceral Adipose Tissue in Overweight Adults: A Systematic Review and Meta-Analysis. Plos One 8(2): e56415.

40. Stanford KI, Middelbeek RJW (2015) Exercise Effects on White Adipose Tissue: Beiging and Metabolic Adaptations. Diabetes 64(9): 23612368.

41. Aldiss P, Betts J, Sale C, Pope M, Budge H, et al. (2018) Exercise-induced 'browning' of adipose tissues. Metabolism 81: 63-70.

42. Sanchez Delgado G, Martinez Tellez B, Olza J, Aguilera CM, Gil A, et al. (2015) Role of Exercise in the Activation of Brown Adipose Tissue. Ann Nutr Metab 67(1): 21-32.

43. Boa B, Yudkin J, Van Hinsbergh V, Bouskela E, Eringa E (2017) Exercise effects on perivascular adipose tissue: Endocrine and paracrine determinants of vascular function. Br J Pharmacol 174(20): 34663481.

44. Choi HY, Kim S, Park JW, Lee NS, Hwang SY, et al. (2014) Implication of Circulating Irisin Levels with Brown Adipose Tissue and Sarcopenia in Humans. J Clin Endocrinol Metab 99(8): 2778-2785.

45. Winn NC, Grunewald ZI, Liu Y, Heden TD, Nyhoff LM, et al. (2017) Plasma Irisin Modestly Increases during Moderate and High-Intensity Afternoon Exercise in Obese Females. Plos One 12(1): e0170690.

\begin{tabular}{l} 
Your next submission with Juniper Publishers \\
will reach you the below assets \\
- Quality Editorial service \\
- Swift Peer Review \\
- Reprints availability \\
- E-prints Service \\
- Manuscript Podcast for convenient understanding \\
- Global attainment for your research \\
- Manuscript accessibility in different formats \\
( Pdf, E-pub, Full Text, Audio) \\
- Unceasing customer service \\
Track the below URL for one-step submission \\
https://juniperpublishers.com/online-submission.php \\
\hline
\end{tabular}

